\title{
Randomised trial of methods of extubation in acute and chronic respiratory distress
}

\author{
Vivien Chan, Anne Greenough
}

\begin{abstract}
Sixty infants (median gestational age 29 weeks) with acute and 60 infants (median gestational age 25 weeks) with chronic respiratory distress were randomised to be extubated either directly into a headbox or onto $3 \mathrm{~cm} \mathrm{H}_{2} \mathrm{O}$ nasal continuous positive airway pressure (CPAP). Our aim was to test the hypothesis that extubation onto nasal CPAP rather than directly into a headbox was more likely to be associated with successful extubation in infants with acute rather than chronic respiratory distress. Overall the failure rate of extubation was approximately $33 \%$, with no significant difference between the infants with acute and chronic respiratory distress. There was no significant difference in the failure rate of extubation among infants randomised to receive nasal CPAP or headbox oxygen in either the acute or chronic respiratory distress groups.

(Arch Dis Child 1993; 68: 570-572)
\end{abstract}

After recovery from respiratory distress, two methods of extubation are generally practised. Infants are either extubated from mechanical ventilation immediately into an appropriate concentration of inspired oxygen delivered into a headbox or they may receive an initial period of continuous positive airway pressure (CPAP) via a nasal cannula. The application of CPAP can improve functional residual capacity, decreasing the likelihood of postextubation atelectasis, 12 and additionally prevent apnoea by improving chest wall stability. ${ }^{3}$ Nasal CPAP, however, has disadvantages. It is associated with trauma to the nostrils, the nasal catheter may block resulting in hypoxia, and infants frequently become agitated due to irritation from the nasal catheter. The advantages of nasal CPAP are likely to be greater in infants who are susceptible to low lung volume, that is those with acute, rather than chronic, respiratory distress and thus nasal CPAP would be predicted to be the superior method of extubation in the former group. The aim of this study was to test that hypothesis by determining in a randomised controlled trial the success of these two extubation methods in infants with acute or chronic respiratory distress.

Department of Child Health, King's College Hospital, London SE5 9RS

Vivien Chan Anne Greenough Correspondence to: Dr Greenough.

Accepted 4 January 1993
Consecutive ventilated infants with a birth weight less than $1800 \mathrm{~g}$ and no congenital abnormalities were recruited into the study. All infants followed the unit's routine policy of weaning during the recovery stage of their illness. The peak inspiratory pressure and ventilator rate were reduced until the peak pressure was below $20 \mathrm{~cm} \mathrm{H}_{2} \mathrm{O}$ and a ventilator rate of 60 breaths/minute (bpm) was reached. Subsequently the peak inspiratory pressure was held constant while the ventilator rate was reduced by extending the expiratory time only. ${ }^{4}$ Aminophylline or theophylline was administered at a ventilator rate of $40 \mathrm{bpm} .^{5}$ Blood gases were measured when clinically indicated (continuous transcutaneous monitoring demonstrated that the arterial oxygen tension was likely to be below $5.33 \mathrm{kPa}$ or above $9.33 \mathrm{kPa}$ ) and routinely every four hours. The inspired oxygen concentration was reduced if the arterial oxygen tension exceeded $9.33 \mathrm{kPa}$. Ventilator rate was decreased if the infant developed a respiratory alkalosis or the blood gases had been maintained over a four hour period. Ventilator rate reduction was in steps of $10 \mathrm{bpm}$ until $30 \mathrm{bpm}$ and then subsequently by $5 \mathrm{bpm}$ until the infant was on endotracheal CPAP. If, after one hour on endotracheal CPAP the infant had not developed a respiratory acidosis $(\mathrm{pH}<7 \cdot 25$ with a carbon dioxide tension $>6.67 \mathrm{kPa}$ ), he or she was extubated.

Before extubation, each infant was assigned to be extubated to either headbox or nasal CPAP ( $3 \mathrm{~cm} \mathrm{H}_{2} \mathrm{O}$ ). Randomisation of extubation assignment was made by drawing sealed envelopes containing the treatment cards, which had been prepared before the start of the study. The cards were stratified according to the presence of acute respiratory distress, that is a postnatal age of less than 14 days (group A) or chronic respiratory distress, a postnatal age equal to or greater than 14 days of age (group B). Infants randomised to headbox received humidified oxygen at the appropriate concentration (including air) for at least 24 hours after extubation. Infants randomised to nasal CPAP were, in addition, nursed in a headbox into which flowed humidified air. The nasal CPAP cannula was routinely changed every 12 hours.

After extubation, oxygenation and heart and respiratory rate were continuously monitored. Arterial blood gases were checked routinely every four hours for at least the first 48 hours after extubation. The extubation method was considered successful if the infant did not require reintubation within the 48 hour period after the initial extubation. Criteria for reintubation were: (i) a respiratory acidodis ( $\mathrm{pH}<7 \cdot 25$ with a carbon dioxide tension $>6.67 \mathrm{kPa}$ ); (ii) requirement for an inspired oxygen concentration above $60 \%$ (continuous monitoring demonstrating the arterial oxygen tension likely to be $<5.33 \mathrm{kPa}$ 
Table 1 Patient characteristics. Results are number or median (range)

\begin{tabular}{lcc}
\hline & Nasal CPAP & Headbox \\
\hline (i) Acute respiratory distress & 30 & 30 \\
No of infants & $29(25-32)$ & $29(25-36)$ \\
Gestational age (weeks) & $1072(688-1672)$ & $1195(710-1740)$ \\
Birth weight (g) & $5(0 \cdot 3-13)$ & $1 \cdot 5(0 \cdot 3-13)$ \\
Postnatal age (days) & 29 & 29 \\
Diagnoses & 1 & 1 \\
$\quad$ RDS/RD of prematurity & & \\
Pneumonia/sepsis & 30 & 30 \\
(ii) Chronic respiratory distress & $25(23-30)$ & $26(23-30)$ \\
No of infants & $735(544-1400)$ & $846(602-1672)$ \\
Gestational age (weeks) & $26(14-57)$ & $28(14-83)$ \\
Birth weight (g) & & 23 \\
Postnatal age (days) & 29 & 1 \\
Diagnoses & 0 & 4 \\
Type I CLD & 0 & 2 \\
Type II CLD & 1 & \\
Pneumonia/sepsis & & \\
Recurrent apnoea & & \\
\hline
\end{tabular}

$\star$ Respiratory distress syndrome/respiratory distress of severe prematurity. ${ }^{13}$ †Type I and type II CLD (chronic lung disease) as defined by Hyde et al. ${ }^{14}$

Table 2 Causes of failure of extubation mode. Results are numbers of infants

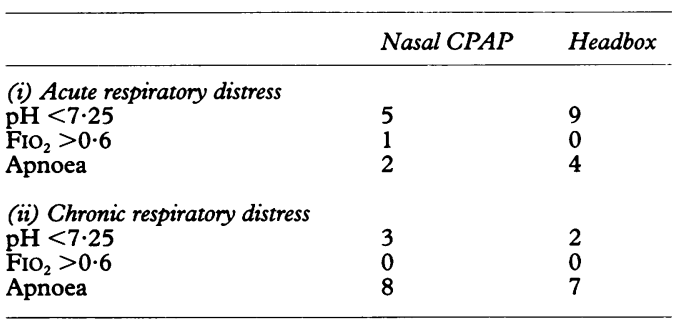

$\mathrm{FIO}_{2}=$ inspired oxygen concentration.

in a lower inspired oxygen concentration); and (iii) recurrent minor or one major apnoea.

ANALYSIS

Differences between groups were assessed for statistical significance using the $\chi^{2}$ test or the Wilcoxon rank sum test as appropriate.

TRIAL SIZE

Before commencing the trial 16 of 50 infants consecutively extubated into a headbox required reintubation within 48 hours. We calculated recruitment of 60 patients with acute and 60 patients with chronic respiratory distress would give us the ability to detect with $80 \%$ power at the $5 \%$ level a change in the success rate of extubation from $78 \%$ in the headbox group to $100 \%$ in the nasal CPAP group.

\section{Patients}

There was no significant difference between the infants randomised to headbox or nasal CPAP in either the acute or chronic respiratory distress groups (table 1). All patients received postextubation physiotherapy to prevent atelectasis. ${ }^{2}$

This study was approved by the King's College Hospital ethics committee.

\section{Results}

ACUTE RESPIRATORY DISTRESS

The extubation mode was successful in 17 infants randomised to headbox and 22 infants randomised to receive nasal CPAP. There was no significant difference between the two groups in the causes of failure of the extubation mode (table 2). The median gestational age of the infants in whom nasal CPAP succeeded was 29 weeks (range 26-32) and 29.5 weeks (range 25-31) in those in whom it failed (nonsignificant). Similarly, there was no significant difference between the gestational ages of infants in whom extubation directly into a headbox succeeded (median 28 weeks, range 25-36) or failed (median 29 weeks, range 26-31). In 13 infants nasal CPAP had to be discontinued within 24 hours of extubation. In seven cases this was due to agitation and in the remaining six because the infant was hyperoxic (arterial oxygen tension $>9.33 \mathrm{kPa}$ ) despite decreasing the inspired oxygen concentration to air.

\section{CHRONIC RESPIRATORY DISTRESS}

The extubation mode was successful in 21 infants randomised to be extubated into a headbox and 19 infants randomised to receive nasal CPAP. There was no significant difference between the two groups in the causes of failure of the extubation mode between the two groups (table 2). The median gestational age of the infants in whom nasal CPAP succeeded was 25 weeks (range 23-30) and in whom it failed 24 weeks (range 23-28) (not significant). Similarly, there was no significant difference between the gestational ages of infants in whom extubation directly into a headbox succeeded (median 26 weeks, range $23-30$ ) or failed (median 26 weeks, range 23-28). In three infants nasal CPAP had to be discontinued within 24 hours of extubation, in two because of agitation and in the third infant because of hyperoxia.

There was no significant difference in the rate of failure of infants with acute or chronic respiratory distress extubated onto nasal CPAP. The causes of failure of extubation, however, did differ significantly between infants with acute or chronic respiratory distress $(p<0.02$; table 2$)$.

\section{Discussion}

Nasal CPAP was no more successful in preventing extubation failure in the infants with acute compared with those with chronic respiratory distress. Thus, these results do not support our hypothesis. Neither, in the two populations, was nasal CPAP more successful than extubation directly into a headbox in preventing failure of the extubation mode. In contrast, in a previous study ${ }^{1}$ none of nine patients randomised to receive nasal CPAP developed postextubation complications compared with six of the nine extubated directly into a headbox. Our trial size was easily sufficient to detect such a difference between the two groups, being more than three times the number of patients that were recruited into the previous study, ${ }^{1}$ thus we do not feel a type 2 error explains the conflicting results. Our infants with both acute and chronic respiratory 
distress were, however, much more immature than the previous group, ${ }^{1}$ but more representative of the present population of premature infants than those enlisted into the study reported 10 years ago. A further difference between the two trials was the level of nasal CPAP used, being $3 \mathrm{~cm} \mathrm{H}_{2} \mathrm{O}$ in the present and $6 \mathrm{~cm} \mathrm{H}_{2} \mathrm{O}$ in the earlier study, ${ }^{1}$ despite their population being all less than 14 days of age. We, ${ }^{6}$ and others, ${ }^{7}$ have demonstrated that in acute respiratory distress syndrome such high levels of CPAP used during ventilation may cause carbon dioxide retention ${ }^{6}$ and impair lung function. ${ }^{7}$ Thus, we do not feel using a higher level of CPAP would have improved our results in the acute respiratory distress group. In support of this conjecture is the finding of similar levels of functional residual capacity and arterial oxygen tension in infants extubated to only $2 \mathrm{~cm} \mathrm{H}_{2} \mathrm{O}$ positive end expiratory pressure compared with levels achieved before extubation. ${ }^{8} \mathrm{~A}$ further argument against using higher levels of CPAP in the group with acute respiratory distress was the high intolerance rate to CPAP and the problem of hyperoxia we found in certain infants.

Infants extubated onto nasal CPAP or headbox followed the same weaning and postextubation protocols. In particular neither group were subjected to a prolonged period of CPAP via the endotracheal tube, which has been previously found to be deleterious, ${ }^{9}$ and both groups received physiotherapy to prevent postextubation atelectasis. ${ }^{2}$ In addition, all infants had received aminophylline or theophylline once the ventilator rate was reduced to 40 bpm. ${ }^{5}$ Thus, perhaps it is not surprising that neither the extubation failure rate nor the causes of failure of extubation differed between those infants who were randomised to receive nasal CPAP or headbox oxygen.

Failure of extubation occurred in approximately one third of both infants with acute and chronic respiratory distress. Interestingly, however, the causes of extubation failure differed significantly between the two groups, apnoea being the commonest cause in the chronic respiratory distress group. The latter group, however, were very immature and this may have explained their greater tendency to apnoea after extubation. ${ }^{10}$ We did not measure lung function before extubation and are not able to comment as to whether this would have improved our extubation success rate but, indeed, the value of such measurements before extubation has been disputed. ${ }^{11} 12$

Our results have failed to demonstrate that extubation onto nasal CPAP rather than directly into a headbox improves extubation success in infants either with acute or chronic respiratory distress. We would therefore recommend that the decision to use nasal CPAP after extubation should be individualised; perhaps postextubation atelectasis might be a suitable criteria.

1 Engelke SC, Roloff DW, Kuhns LR. Post-extubation nasal continuous positive airway pressure. Arch Dis Child 1982; 136: 359-61.

2 Finer NN, Moriartey RR, Boyd J, Phillips HJ, Stewart AR, Ulan O. Post-extubation atelectasis: a retrospective review and prospective controlled study. $\mathcal{f}$ Pediatr 1979; 94: and pros.

3 Martin RJ, Nearman HS, Katona PG, et al. The effect of a low continuous positive airway pressure on the reflex control of respiration in the preterm infant. $\mathcal{F}$ Pediatr 1977; 90: $970-81$.

4 Greenough A, Pool J, Gamsu H. A randomised controlled trial of two methods of weaning from high frequency positive pressure ventilation. Arch Dis Child 1989; 64: 834-8.

5 Greenough A, Elias Jones A, Pool J, Morley CJ, Davis J. The therapeutic actions of theophylline in preterm ventilated infants. Early Hum Dev 1985; 12: 15-22.

6 Greenough A, Chan V, Hird MF. Positive and expiratory pressure in acute and chronic neonatal respiratory dispressure in acute and chronic neona

7 Field D, Milner AD, Hopkin IE. Effects of positive end expiratory pressure during ventilation of the preterm infant. Arch Dis Child 1985; 60: 843-7.

8 Berman LS, Fox WW, Raphaely RC, et al. Optimum levels of CPAP for tracheal extubation of newborn infants. 7 Pediatr 1976; 89: 109-12.

$9 \mathrm{Kim} \mathrm{EH}$, Boutwell WC. Successful direct extubation of very low birthweight infants from low intermittent mandatory ventilation rate. Pediatrics $1987 ; 80$ : 409-14.

10 Henderson-Smart DJ. The effect of gestational age on the incidence and duration of recurrent apnoea in newborn babies. Australian Paediatric fournal 1981; 17: 273-6.

11 Balsan MJ, Jones JG, Watchko JF, Guthrie RF. Measurement of pulmonary mechanics prior to the elecMeasurement of pulmonary mechanics prior to the elective extubat $238-43$.

12 Veness-Meehan KA, Richter S, Davis JM. Pulmonary function testing prior to extubation in infants with respiratory distress syndrome. Pediatr Pulmonol 1990; 9: 2-6.

13 Chan V, Greenough A, Gamsu HR. Neonatal complications of extreme prematurity in mechanically ventilated infants. Eur $\mathcal{F}$ Pediatr 1992; 151: 693-6.

14 Hyde I, English RE, Williams JA. The changing pattern of chronic lung disease of prematurity. Arch Dis Child 1989; 64: 448-51. 